\title{
The Chebyshev Wavelet Method for Numerical Solutions of A Fractional Oscillator
}

\author{
E. Hesameddini, S. Shekarpaz, Habibolla Latifizadeh \\ Department of Mathematics, Faculty of Basic Sciences, Shiraz University of \\ Technology, Modarres Bld. P.O. Box, 71555-313, Shiraz, Iran \\ E-mails: Hesameddini@sutech.ac.ir, S.Shekarpaz@ sutech.ac.ir \\ H.Latifi.62.math@sutech.ac.ir
}

\begin{abstract}
Wavelet transform or wavelet analysis has been recently developed as a mathematical tool for many problems. This paper is concerned with the wavelet numerical method for solving partial differential equations (PDE's). The method is based on discrete wavelet transform, using Chebyshev Wavelet Method (CWM) which can be used for solving fractional differential equations. Interest in solving the problem using the Chebyshev wavelet basis is due to its simplicity and efficiency in numerical approximations. Four numerical examples were shown and the results demonstrated that the proposed way can be quite reasonable while compared with exact solutions.
\end{abstract}

Keywords: Chebyshev Wavelet Method, Fractional Oscillator

2000 mathematical Subject classification: Primary 65T60. Secondary $34 \mathrm{~A} 34$.

\section{Introduction}

Mathematical model of a system usually consists of solving ordinary and partial differential equations [1,2]. Adaptive numerical techniques for approximating the numerical solutions of these equations have attracted the attention of researchers since many years ago [3]. Several different methods have been applied for solving these problems, which include finite difference method, finite element method, Laplace transform method and other numerical methods. During previous years, the issue of wavelets has influenced major regions of pure and applied 
mathematics, especially in the numerical analysis of differential equations [4,5]. Wavelets are established as a strong novel mathematical implement in signal processing, turbulence problem, simulation and time-series analysis $[6,7,8]$.

In the recent years, strenuous action and interest have been shown in the usage of wavelet theory and it's related multiresolution analysis [4,9]. The substantial scheme back of the wavelet decomposition is the compressing representation of wavelet-based functions. In wavelet methods, the geometric region and functions are represented in terms of wavelet series defined in a certain domain. Also, by transforming the differential equations to some weak forms, all of them along with the unknown functions can be represented on the same basis $[10,11,12]$. Another region of remarkable interest is the study of fractional differential equations [9].In this paper, the dynamics of the so-called driven fractional oscillator is probed. This fractional oscillators are obtained by replacing the second-time derivative term in the corresponding harmonic oscillator by a fractional derivative of the order $\alpha$ considering that $1<\alpha \leq 2$. The fractional derivatives were considered in the Caputo sense $[13,14]$. The general response expression contains a parameter describing the order of the fractional derivative that can be varied in order to obtain various responses. In the case of $\alpha=2$, the fractional system of oscillators reduces to the standard system of simple harmonic oscillators. Some aspects of such a system have been studied previously by other researchers [14]. The aim of this paper is to solve these problems via a novel method based on Chebyshev wavelets $[15,16,17,18]$. So, in order to obtain solutions for fractional oscillators, compactly supported, orthonormal and continuous wavelets are applied, which are especially constructed for the bounded interval. Since chebyshev wavelets combine orthogonality with localization and scaling properties, naturally, there is an attempt to use these functions for the numerical approximation solutions of PDE's [19]. The method presented here consists of reducing fractional differential equation to a set of nonlinear equations by expanding unknown functions in terms of wavelets with unknown coefficients. The properties of scaling functions and wavelets [20] are then utilized for evaluating the unknown coefficients.

This paper is organized as follows: in Section 2, some preliminary definitions of the fractional calculus are presented. Section 3, is devoted to the multiresolution approximations and wavelets to formulate the chebyshev wavelets. In Section 4, the proposed method is used for approximating the solutions of fractional differential equations. And finally, the numerical results are expressed in Section 5.

\section{Some Preliminary Definition of the Fractional Calculus}

In this section, some required definitions and mathematical notations of fractional calculus theory which are applied in this paper are given. 
Definitions 2.1: A real function $\mathrm{f}(\mathrm{x}), x>0$ is said to be in the space $\mathrm{C}_{\mu}, \mu \in \mathrm{R}$ if there exists a real number $\mathrm{p}(>\mu)$ such that $\mathrm{f}(\mathrm{x})=\mathrm{x}^{\mathrm{p}_{1}} \mathrm{f}_{1}(\mathrm{x})$ where $\mathrm{f}_{1}(\mathrm{x}) \in \mathrm{C}[0, \infty)$ and is said to be in the space $_{C_{\mu}}^{\mathrm{m}}, \mathrm{m} \in \mathrm{NU}\{0\}$, if $\mathrm{f}^{(\mathrm{m})} \in \mathrm{C}_{\mu}, \mathrm{m} \in \mathrm{N}$.

Definitions 2.2: The Riemann-Liouville fractional integral operator of order $\alpha \geq 0$, of a functional $\mathrm{f} \in \mathrm{C}_{\mu}, \mu \geq-1$ is defined as

$$
\begin{gathered}
\mathrm{J}^{\alpha} \mathrm{f}(\mathrm{x})=\frac{1}{\Gamma(\alpha)} \int_{0}^{x}(\mathrm{x}-\xi)^{\alpha-1} \mathrm{f}(\xi) \mathrm{d} \xi \quad \alpha>0, \mathrm{x}>0 . \\
\mathrm{J}^{0} \mathrm{f}(\mathrm{x})=\mathrm{f}(\mathrm{x}) .
\end{gathered}
$$

Properties of the operator $\mathrm{J}^{\alpha}[18,19]$ are mentioned in the following way:

for $\mathrm{f} \in \mathrm{C}_{\mu}, \mu \geq-1, \alpha, \beta>0, \mu \geq-1$ and $\gamma \geq-1$,

1) $J^{\alpha} f(x)$ exists for almost every $x \in[a, b]$

2) $J^{\alpha} J^{\beta} f(x)=J^{\alpha+\beta} f(x)$.

3) $J^{\alpha} J^{\beta} f(x)=J^{\beta} J^{\alpha} f(x)$,

4) $\mathrm{J}_{\mathrm{a}}^{\alpha}(\mathrm{x}-\mathrm{a})^{\gamma}=\frac{\Gamma(\gamma+1)}{\Gamma(\alpha+\gamma+1)}(\mathrm{x}-\mathrm{a})^{\alpha+\gamma}$.

Definitions 2.3: The fractional derivative of $f(x)$ in Caputo sense is defined as

$\mathrm{D}^{\alpha} \mathrm{f}(\mathrm{x})=\mathrm{J}^{\mathrm{m}-\alpha} \mathrm{D}^{\mathrm{m}} \mathrm{f}(\mathrm{x})=\frac{1}{\Gamma(\mathrm{m}-\alpha)} \int_{0}^{\mathrm{x}}(\mathrm{x}-\xi)^{\mathrm{m}-\alpha-1} \mathrm{f}^{(\mathrm{m})}(\xi) \mathrm{d} \xi$

for $\mathrm{m}-1<\alpha \leq \mathrm{m}, \mathrm{m} \in \mathrm{N}, x>0, \mathrm{f} \in \mathrm{C}_{-1}^{\mathrm{m}}[17]$.

Also, two basic properties of the Capoto's fractional derivative are needed which are described in the following forms;

Lemma 2.1: If $\mathrm{m}-1<\alpha \leq \mathrm{m}, \mathrm{m} \in \mathrm{N}$ and $\mathrm{f} \in \mathrm{C}_{\mu}^{\mathrm{m}}, \mu \geq-1$ then

$$
D^{\alpha}{ }^{\alpha} f(x)=f(x),
$$

and

$$
\mathrm{J}^{\alpha} \mathrm{D}^{\alpha} \mathrm{f}(\mathrm{x})=\mathrm{f}(\mathrm{x})-\sum_{\mathrm{k}=0}^{\mathrm{m}-1} \mathrm{f}^{(\mathrm{k})}\left(0^{+}\right) \frac{\mathrm{x}^{\mathrm{k}}}{\mathrm{k} !}, \quad \mathrm{x}>0
$$

The Caputo fractional derivative is perused here whereas it allows traditional initial and boundary conditions to be included in the formulation of the problem. 
Definitions 2.4. For $m$ to be the smallest integer that exceeds $\alpha$, the Caputo time-fractional derivative operator of the order $\alpha>0$. is defined as follows;

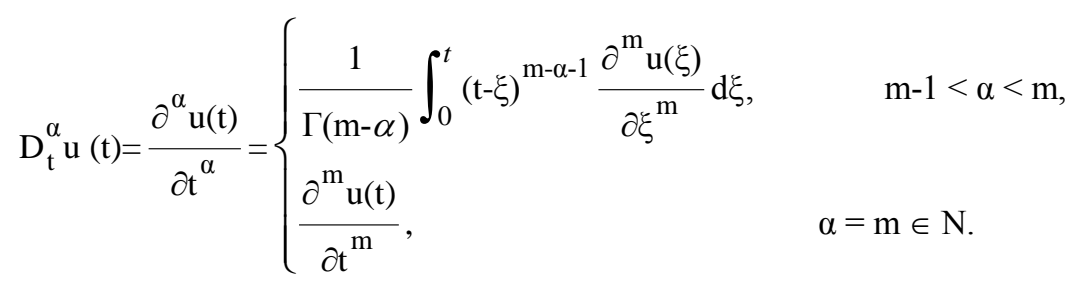

For more information on the mathematical properties of fractional derivatives and integrals, see $[9,13,14,16,17,18,19]$.

For real $\alpha>0$ (later, only for $1<\alpha \leq 2$ ), consider the fractional differential equation

$$
\frac{d^{\alpha} u}{d t^{\alpha}}+\omega^{\alpha} u(t)=f(t), \quad m-1<\alpha \leq m,
$$

subject to the initial conditions

$$
\mathrm{u}^{\mathrm{k}}(0)=\mathrm{c}_{\mathrm{k}}, \quad \mathrm{k}=0,1, \ldots, \mathrm{m}-1,
$$

where $\omega$ is an arbitrary constant and $f(t)$ a given continuous function. Here, $m$ is an integer uniquely defined by $m-1<\alpha \leq \mathrm{m}$, which provides the number of the prescribed initial values $\mathrm{u}^{\mathrm{k}}(0)=\mathrm{c}_{\mathrm{k}}, \mathrm{k}=0,1, \ldots, \mathrm{m}-1$. Equation (3) is called the fractional oscillation equation for $1<\alpha \leq 2$, the fractional relaxation equation for $0<\alpha \leq 1$ and the fractional growing oscillation equation corresponding to $2<\alpha \leq 3$. The fractional derivative in Equation (3) is considered in Caputo sense.

\section{Chebyshev Wavelets and their Properties}

In this section, the general definitions of wavelets are introduced. Also, the Chebyshev wavelets and their main properties are illustrated.

\subsection{Wavelets and Chebyshev Wavelets}

Wavelets are a family of functions which are derived from the family of scaling functions $\left\{\phi_{j, k}: k \in Z\right\}$ where

$\phi(\mathrm{t})=\sum_{k} \mathrm{a}_{\mathrm{k}} \phi(2 \mathrm{t}-\mathrm{k})$. 
For the continuous wavelet, the following form can be presented:

$$
\psi_{\mathrm{a}, \mathrm{b}}(\mathrm{t})=|\mathrm{a}|^{-\frac{1}{2}} \psi\left(\frac{\mathrm{t}-\mathrm{b}}{\mathrm{a}}\right) \quad \mathrm{a}, \mathrm{b} \in \mathrm{R}, \mathrm{a} \neq 0,
$$

where $\mathrm{a}$ and $\mathrm{b}$ are dilation and translation parameters, respectively, such that $\psi(\mathrm{x})$ is a single wavelet function. If $\mathrm{a}$ and $\mathrm{b}$ are discrete values in the initial form of the continuous wavelets,

$$
\begin{array}{ll}
\mathrm{a}=\mathrm{a}_{0}^{-\mathrm{j}}, & \mathrm{a}_{0}>1, \quad \mathrm{~b}_{0}>0, \\
\mathrm{~b}=\mathrm{n} \mathrm{b}_{0} \mathrm{a}_{0}^{-\mathrm{j}}, & \mathrm{j}, \mathrm{k} \in \mathrm{Z},
\end{array}
$$

then, the family of discrete wavelets are shown as follows:

$$
\psi_{\mathrm{j}, \mathrm{k}}(\mathrm{t})=\left|\mathrm{a}_{0}\right|^{\frac{\mathrm{j}}{2}} \psi\left(\mathrm{a}_{0}^{\mathrm{j}} \mathrm{t}-\mathrm{nb}_{0}\right)
$$

where, $\left\{\psi_{\mathrm{j}, \mathrm{k}}\right\}_{\mathrm{j} \in \mathrm{Z}}$ forms a wavelet basis for $\mathrm{L}^{2}(\mathrm{R})$. Also, an orthonormal basis is constructed for $a_{0}=2$ and $\mathrm{b}_{0}=1$. Four parameters contribute to the general form of Chebyshev Wavelets, $m$ is the degree of Chebyshev polynomials of the first kind, $\mathrm{n}=1,2, \ldots, 2^{\mathrm{k}-1}, k$ is any positive integer and $t$ denotes the time. Consequently, Chebyshev Wavelets are in the following form:

$$
\psi_{n, m}(t)=\left\{\begin{array}{lr}
2^{\frac{k}{2}} \tilde{T}_{m}\left(2^{k} t-2 n+1\right) & \frac{n-1}{2^{k}} \leq x<\frac{n}{2^{k}} \\
0 & \text { otherwise }
\end{array}\right.
$$

where $\mathrm{m}=0,1,2, \ldots, \mathrm{M}-1, \mathrm{k}=1,2, \ldots, 2^{\mathrm{j}-1}$ and,

$$
\tilde{\mathrm{T}}_{\mathrm{m}}(\mathrm{t})= \begin{cases}\frac{1}{\sqrt{\pi}}, & \mathrm{m}=0, \\ \sqrt{\frac{2}{\pi}} \mathrm{T}_{\mathrm{m}}(\mathrm{t}), & \mathrm{m}>0,\end{cases}
$$

where $\mathrm{T}_{\mathrm{m}}(\mathrm{t})$ are the Chebyshev polynomials. Then, by (8), the wavelets $\left\{\psi_{\mathrm{n}, \mathrm{m}}\right\}$ form an orthonormal basis for $\mathrm{L}^{2}[0,1]$. In the above formulation of Chebyshev wavelets, the Chebyshev polynomials are shown as follows: 


$$
\begin{aligned}
& \mathrm{T}_{0}(\mathrm{t})=1, \\
& \mathrm{~T}_{1}(\mathrm{t})=\mathrm{t}, \\
& \mathrm{T}_{\mathrm{m}+1}(\mathrm{t})=2 \mathrm{t} \mathrm{T}_{\mathrm{m}}(\mathrm{t})-\mathrm{T}_{\mathrm{m}-1}(\mathrm{t}), \quad \mathrm{m}=1,2, \ldots
\end{aligned}
$$

which are orthogonal with respect to the weight function $\omega(t)=\frac{1}{\sqrt{1-t^{2}}}$ on the interval $[-1,1]$.

Because of the orthogonality, in this form of Chebyshev wavelets the weight function $\tilde{\omega}(\mathrm{t})=\omega(2 \mathrm{t}-1)$ should be dilated and translatd to $\omega_{\mathrm{n}}(\mathrm{t})=\omega\left(2^{\mathrm{k}} \mathrm{t}-2 \mathrm{n}+1\right)$.

\subsection{Function Approximation}

A given function $\mathrm{u}(\mathrm{t})$ with the domain $[0,1]$ may be approximated as:

$$
\mathrm{u}(\mathrm{t})=\sum_{\mathrm{n}=1}^{\infty} \sum_{\mathrm{m}=0}^{\infty} \mathrm{c}_{\mathrm{n}, \mathrm{m}} \psi_{\mathrm{n}, \mathrm{m}}(\mathrm{t})
$$

If the infinite series in Eq. (9) is truncated, then this equation can be written as:

$$
u(t) \simeq \sum_{n=1}^{2^{j-1}} \sum_{m=0}^{M-1} c_{n, m} \psi_{n, m}(t)=C^{T} \cdot \Psi(t)
$$

where $\mathrm{C}$ and $\Psi(\mathrm{t})$ are matrices of size $\left(2^{\mathrm{k}-1} \mathrm{M} \times 1\right)$ as follows:

$$
\begin{aligned}
& \mathrm{C}=\left[\mathrm{c}_{1,0}, \mathrm{c}_{1,1}, \ldots, \mathrm{c}_{1, \mathrm{M}-1}, \mathrm{c}_{2,0}, \mathrm{c}_{2,1}, \ldots, \mathrm{c}_{2, \mathrm{M}-1}, \ldots, \mathrm{c}_{2^{\mathrm{k}-1}, 0}, \mathrm{c}_{2^{\mathrm{k}-1}, 1}, \ldots, \mathrm{c}_{2^{\mathrm{k}-1}, \mathrm{M}-1}\right]^{\mathrm{T}}, \\
& \Psi(\mathrm{t})=\left[\psi_{1,0}, \psi_{1,1}, \ldots, \psi_{1, \mathrm{M}-1}, \psi_{2,0}, \psi_{2,1}, \ldots, \psi_{2, \mathrm{M}-1}, \ldots, \psi_{2^{\mathrm{k}-1}, 0}, \psi_{2^{\mathrm{k}-1}, 1}, \ldots, \psi_{2^{\mathrm{k}-1}, \mathrm{M}-1}\right]^{\mathrm{T}} .
\end{aligned}
$$

Let $\left\{t_{i}\right\}_{i=1}^{2^{k-1} M}$ be a set of collocation points as follows:

$$
\mathrm{t}_{\mathrm{i}}=\frac{(2 \mathrm{i}-1)}{2^{\mathrm{k}} \mathrm{M}}, \quad \mathrm{i}=1,2, \ldots, 2^{\mathrm{k}-1} \mathrm{M}
$$

Thus, the Chebyshev wavelet matrix $\Psi_{\mathrm{m} \times \mathrm{m}}$ can be defined as:

$$
\Psi_{\mathrm{m} \times \mathrm{m}}=\left[\begin{array}{lll}
\Psi\left(\frac{1}{2 \mathrm{~m}}\right) & \Psi\left(\frac{3}{2 \mathrm{~m}}\right) \quad \ldots \quad \Psi\left(\frac{2 \mathrm{~m}-1}{2 \mathrm{~m}}\right)
\end{array}\right] .
$$

For instance, when $\mathrm{k}=2$ and $\mathrm{M}=3$, the following matrix can be presented: 


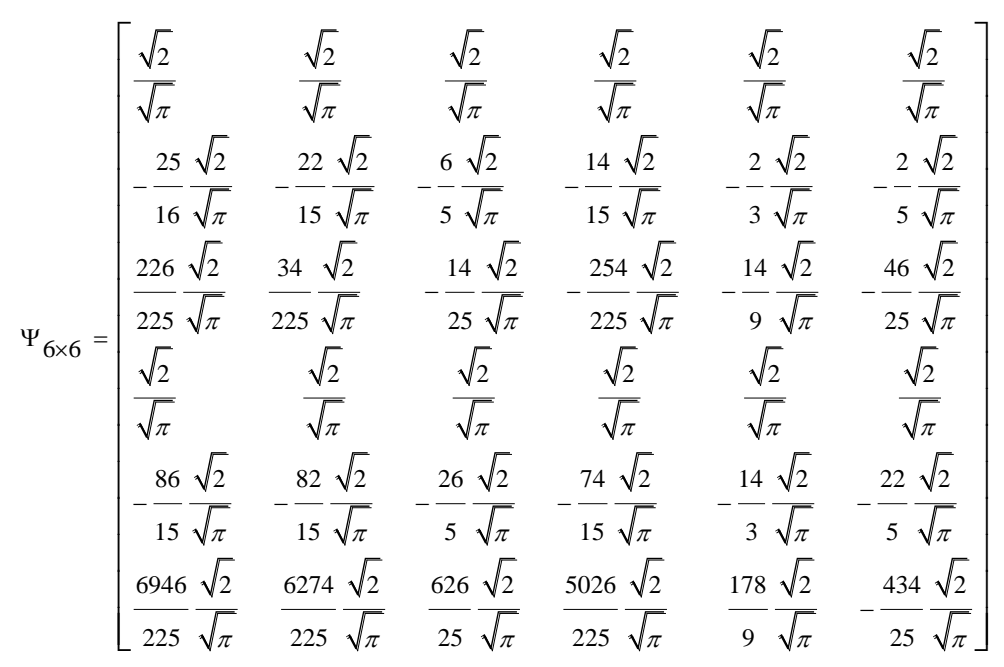

\section{Application of the CWM for Solving Fractional Differential Equations}

In this section, the CWM is applied for solving a system of driven fractional oscillators with the common form as follows;

$\frac{d^{\alpha} u}{d t^{\alpha}}+\omega^{\alpha} u(t)=f(t), \quad 1<\alpha \leq 2$,

with the initial conditions;

$\mathrm{u}(0)=\mathrm{a}, \quad \mathrm{u}(0)=\mathrm{b}$,

where $\omega$ is the natural frequency and $f(t)$ is a given continuous function. By applying the CWM for approximating the solutions of this problem, (13) can be rewritten as follows;

$\frac{d^{\alpha}}{d t^{\alpha}}\left(\sum_{n=1}^{2^{k-1}} \sum_{m=0}^{M-1} c_{n, m} \psi_{n, m}(t)\right)+\omega^{\alpha}\left(\sum_{n=1}^{2^{k-1}} \sum_{m=0}^{M-1} c_{n, m} \psi_{n, m}(t)\right)=f(t), \quad 1<\alpha \leq 2$,

with: 
$\sum_{n=1}^{2^{k-1}} \sum_{m=0}^{M-1} c_{n, m} \psi_{n, m}(0)=a$

$\sum_{n=1}^{2^{k-1}} \sum_{m=0}^{M-1} c_{n, m}\left(\frac{d}{d t} \psi_{n, m}(t)\right)(0)=b$

where $f(t)=\sum_{n^{\prime}=1}^{2^{k-1}} \sum_{m^{\prime}=0}^{M-1} c_{n^{\prime}, m^{\prime}} \psi_{n^{\prime}, m^{\prime}}(t)$, and $\frac{d^{\alpha}}{d t^{\alpha}} u(t)$ is the fractional derivative of a given function $\mathrm{u}(\mathrm{t})$, defined in $\operatorname{Section}(2)$.

Here, let $\left\{t_{i}\right\}_{i=1}^{2^{k-1} M}$ be a set of collocation points, then Eq. (15) can be calculated at $\left\{\mathrm{t}_{\mathrm{i}}\right\}$ collocation points, such that

$$
\frac{\mathrm{d}^{\alpha}}{\mathrm{d} \mathrm{t}^{\alpha}}\left(\sum_{\mathrm{n}=1}^{2^{k-1}} \sum_{\mathrm{m}=0}^{\mathrm{M}-1} \mathrm{c}_{\mathrm{n}, \mathrm{m}} \psi_{\mathrm{n}, \mathrm{m}}\left(\mathrm{t}_{\mathrm{i}}\right)\right)+\omega^{\alpha}\left(\sum_{\mathrm{n}=1}^{2^{k-1}} \sum_{\mathrm{m}=0}^{\mathrm{M}-1} \mathrm{c}_{\mathrm{n}, \mathrm{m}} \psi_{\mathrm{n}, \mathrm{m}}\left(\mathrm{t}_{\mathrm{i}}\right)\right)=\mathrm{f}\left(\mathrm{t}_{\mathrm{i}}\right), \quad 1<\alpha \leq 2,
$$

and the initial conditions are in the following form:

$$
\begin{aligned}
& \sum_{\mathrm{n}=1}^{2^{k-1}} \sum_{\mathrm{m}=0}^{\mathrm{M}-1} \mathrm{c}_{\mathrm{n}, \mathrm{m}} \psi_{\mathrm{n}, \mathrm{m}}\left(\mathrm{t}_{0}\right)=\mathrm{a}, \\
& \sum_{\mathrm{n}=1}^{2^{k-1}} \sum_{\mathrm{m}=0}^{\mathrm{M}-1} \mathrm{c}_{\mathrm{n}, \mathrm{m}}\left(\frac{\mathrm{d}}{\mathrm{dt}} \psi_{\mathrm{n}, \mathrm{m}}(\mathrm{t})\right)\left(\mathrm{t}=\mathrm{t}_{0}\right)=\mathrm{b} .
\end{aligned}
$$

Thus, by evaluating the coefficients $\left\{c_{n, m}\right\}, \mathrm{u}(\mathrm{t})$ can be obtained at every chosen point.

\section{Numerical Results}

In order to demonstrate the validity of the proposed method, three examples are examined and the approximations of solutions are compared with the exact solutions or solutions obtained using other methods.

Example 1. Consider the following system:

$$
\frac{d^{\alpha} u}{\mathrm{~d} \mathrm{t}^{\alpha}}+\omega^{\alpha} \mathrm{u}(\mathrm{t})=0, \quad 1<\alpha \leq 2
$$

subject to the initial conditions; 
$\mathrm{u}(0)=1, \quad \dot{\mathrm{u}}(0)=0$,

A simple harmonic fractional oscillator is described using this equation and the forcing function in this case is $f(t)=0$. Thus by inserting Eq. (10) in Eq. (17), the following can be presented,

$$
\frac{\mathrm{d}^{\alpha}}{\mathrm{dt}^{\alpha}}\left(\sum_{\mathrm{n}=1}^{\mathrm{k}^{\mathrm{k}-1}} \sum_{\mathrm{m}=0}^{\mathrm{M}-1} \mathrm{c}_{\mathrm{n}, \mathrm{m}} \psi_{\mathrm{n}, \mathrm{m}}(\mathrm{t})\right)+\omega^{\alpha}\left(\sum_{\mathrm{n}=1}^{\mathrm{k}^{\mathrm{k}-1}} \sum_{\mathrm{m}=0}^{\mathrm{M}-1} \mathrm{c}_{\mathrm{n}, \mathrm{m}} \psi_{\mathrm{n}, \mathrm{m}}(\mathrm{t})\right)=0, \quad 1<\alpha \leq 2
$$

with the initial conditions;

$$
\begin{aligned}
& \sum_{n=1}^{2^{k-1}} \sum_{m=0}^{M-1} c_{n, m} \psi_{n, m}(0)=1, \\
& \sum_{n=1}^{2^{k-1}} \sum_{m=0}^{M-1} c_{n, m}\left(\frac{d}{d t} \psi_{n, m}(t)\right)(t=0)=0,
\end{aligned}
$$

By collocating the above equation in collocation points $\left\{\mathrm{t}_{\mathrm{i}}\right\}_{\mathrm{i}=1}^{2^{k-1} \mathrm{M}}$, one can gets:

$$
\frac{\mathrm{d}^{\alpha}}{\mathrm{d} \mathrm{t}^{\alpha}}\left(\sum_{\mathrm{n}=1}^{2^{\mathrm{k}-1}} \sum_{\mathrm{m}=0}^{\mathrm{M}-1} \mathrm{c}_{\mathrm{n}, \mathrm{m}} \psi_{\mathrm{n}, \mathrm{m}}\left(\mathrm{t}_{\mathrm{i}}\right)\right)+\omega^{\alpha}\left(\sum_{\mathrm{n}=1}^{2^{\mathrm{k}-1}} \sum_{\mathrm{m}=0}^{\mathrm{M}-1} \mathrm{c}_{\mathrm{n}, \mathrm{m}} \psi_{\mathrm{n}, \mathrm{m}}\left(\mathrm{t}_{\mathrm{i}}\right)\right)=0, \quad 1<\alpha \leq 2
$$

with

$$
\begin{aligned}
& \sum_{n=1}^{2^{k-1}} \sum_{m=0}^{M-1} c_{n, m} \psi_{n, m}(0)=1, \\
& \sum_{n=1}^{2^{k-1}} \sum_{m=0}^{M-1} c_{n, m}\left(\frac{d}{d t} \psi_{n, m}(t)\right)(t=0)=0,
\end{aligned}
$$

Next, by computing the coefficients $\left\{c_{n, m}\right\}$, the solutions $\mathrm{u}(\mathrm{t})$ of this equation are obtained. The numerical results of this problem with $\alpha=1.7, \alpha=1.9$ and $\alpha=2$ are presented in Table 1. By setting $\alpha=2$ in Eq. (17), the solution of a simple harmonic oscillator is obtained and expressed by $u(t)=\cos (\omega t)$. 
Table 1: Numerical results compared with the results in [21] by $\omega=0.5$.

(Example 1)

\begin{tabular}{cccccccc} 
& $\alpha=1.7$ & & \multicolumn{2}{c}{$\alpha=1.9$} & \multicolumn{2}{c}{$\alpha=2$} \\
t & Our method & $\operatorname{Ref}[21]$ & Our method & $\operatorname{Ref}[21]$ & & Our method & Ref[21] \\
\hline 0.0 & 1 & 1 & 1 & 1 & 1 & 1 \\
0.1 & 0.998 & 0.996 & 0.998 & 0.998 & 0.998 & 0.998 \\
\hline 0.2 & 0.992 & 0.987 & 0.994 & 0.993 & 0.995 & 0.995 \\
0.3 & 0.984 & 0.974 & 0.988 & 0.985 & 0.989 & 0.988 \\
0.4 & 0.973 & 0.958 & 0.979 & 0.974 & 0.981 & 0.980 \\
0.5 & 0.961 & 0.939 & 0.969 & 0.960 & 0.970 & 0.968 \\
0.6 & 0.947 & 0.918 & 0.956 & 0.945 & 0.958 & 0.955 \\
0.7 & 0.932 & 0.894 & 0.941 & 0.926 & 0.943 & 0.939 \\
0.8 & 0.916 & 0.867 & 0.925 & 0.905 & 0.927 & 0.921 \\
\hline 0.9 & 0.899 & 0.839 & 0.908 & 0.882 & 0.909 & 0.900 \\
1.0 & 0.882 & 0.809 & 0.890 & 0.857 & 0.880 & 0.877
\end{tabular}

Figure 1 demonstrates the progress results for $\alpha=2, \alpha=1.9$ and $\alpha=1.7$. The comparison of these results shows how the relocation of the fractional oscillator varies as a function of time and how this time change depends on the parameter $\alpha$. Also, the behavior of the driven fractional oscillator is similar to that of the damped harmonic oscillator, where the locomotion is yet oscillatory, whereas the assembled energy decreases and the phase plane diagram is no longer a closed curve, but a logarithmic spiral. The results of these computations, for different values of $\alpha$, are convergent to the solutions obtained by setting $\alpha=2$.
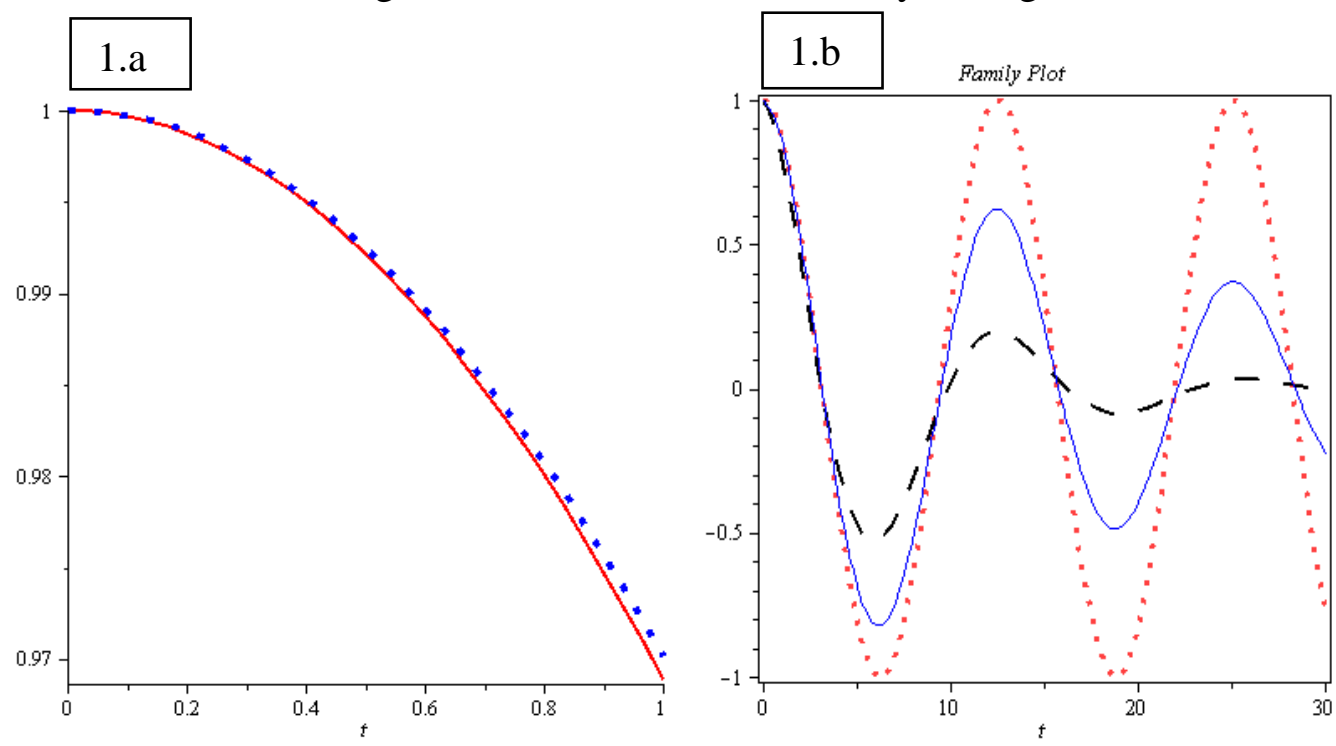

Figure 1. a. The solution obtained by the wavelet method (--) and analytical method (-) with $\omega=0.25$.

Figure 1. b. The exact solution of a simple harmonic oscillator

$$
\alpha=2(\ldots), \alpha=1.9(-), \alpha=1.7(--) \text { by } \omega=0.5 \text {. }
$$


Example 2. Now, the following fractional differential equation is considered:

$\frac{d^{\alpha} u}{d t^{\alpha}}+\omega^{\alpha} u(t)=0, \quad 1<\alpha \leq 2$

Which is subject to the following initial conditions

$$
\mathrm{u}(0)=\mathrm{c}, \quad \dot{\mathrm{u}}(0)=0
$$

where the forcing function is the step function that is defined by

$$
f(t)= \begin{cases}A, & t>0 \\ 0, & t<0\end{cases}
$$

Similar to the procedure used in Example.1, (21) can be written as

$$
\frac{\mathrm{d}^{\alpha}}{\mathrm{dt}^{\alpha}}\left(\sum_{\mathrm{n}=1}^{\mathrm{k}^{\mathrm{k}-1}} \sum_{\mathrm{m}=0}^{\mathrm{M}-1} \mathrm{c}_{\mathrm{n}, \mathrm{m}} \psi_{\mathrm{n}, \mathrm{m}}(\mathrm{t})\right)+\omega^{\alpha}\left(\sum_{\mathrm{n}=1}^{2^{\mathrm{k}-1}} \sum_{\mathrm{m}=0}^{\mathrm{M}-1} \mathrm{c}_{\mathrm{n}, \mathrm{m}} \psi_{\mathrm{n}, \mathrm{m}}(\mathrm{t})\right)=\mathrm{A}, \quad 1<\alpha \leq 2, \mathrm{t}>0
$$

with;

$$
\begin{aligned}
& \sum_{\mathrm{n}=1}^{2^{k-1}} \sum_{\mathrm{m}=0}^{\mathrm{M}-1} \mathrm{c}_{\mathrm{n}, \mathrm{m}} \psi_{\mathrm{n}, \mathrm{m}}(0)=\mathrm{c} \\
& \sum_{\mathrm{n}=1}^{2^{k-1}} \sum_{\mathrm{m}=0}^{\mathrm{M}-1} \mathrm{c}_{\mathrm{n}, \mathrm{m}}\left(\frac{\mathrm{d}}{\mathrm{dt}} \psi_{\mathrm{n}, \mathrm{m}}(\mathrm{t})\right)(\mathrm{t}=0)=0
\end{aligned}
$$

Then, by substituting the collocation points $\left\{\mathrm{t}_{\mathrm{i}}\right\}_{\mathrm{i}=1}^{2^{k-1} \mathrm{M}}$, this formula can be presented:

$$
\frac{\mathrm{d}^{\alpha}}{\mathrm{d} \mathrm{t}^{\alpha}}\left(\sum_{\mathrm{n}=1}^{2^{k-1}} \sum_{\mathrm{m}=0}^{\mathrm{M}-1} \mathrm{c}_{\mathrm{n}, \mathrm{m}} \psi_{\mathrm{n}, \mathrm{m}}\left(\mathrm{t}_{\mathrm{i}}\right)\right)+\omega^{\alpha}\left(\sum_{\mathrm{n}=1}^{2^{\mathrm{k}-1}} \sum_{\mathrm{m}=0}^{\mathrm{M}-1} \mathrm{c}_{\mathrm{n}, \mathrm{m}} \psi_{\mathrm{n}, \mathrm{m}}\left(\mathrm{t}_{\mathrm{i}}\right)\right)=0, \quad 1<\alpha \leq 2
$$

with

$$
\begin{aligned}
& \sum_{\mathrm{n}=1}^{2^{k-1}} \sum_{\mathrm{m}=0}^{\mathrm{M}-1} \mathrm{c}_{\mathrm{n}, \mathrm{m}} \psi_{\mathrm{n}, \mathrm{m}}(0)=\mathrm{c}, \\
& \sum_{\mathrm{n}=1}^{2^{k-1}} \sum_{\mathrm{m}=0}^{\mathrm{M}-1} \mathrm{c}_{\mathrm{n}, \mathrm{m}}\left(\frac{\mathrm{d}}{\mathrm{dt}} \psi_{\mathrm{n}, \mathrm{m}}(\mathrm{t})\right)(\mathrm{t}=0)=0 .
\end{aligned}
$$

After computing the coefficients $\left\{\mathrm{c}_{\mathrm{n}, \mathrm{m}}\right\}$, solutions $\mathrm{u}(\mathrm{t})$ for this equation are obtained. The numerical results of this problem with $\alpha=1.7, \alpha=1.9$ and $\alpha=2$ are shown in Table 2. 
Table 2. Numerical results compared with the results in [21] by $\omega=0.25$.

\begin{tabular}{ccccccc} 
& $\alpha=1.7$ & \multicolumn{3}{c}{$\alpha=1.9$} & \multicolumn{2}{c}{$\alpha=2$} \\
$\mathrm{t}$ & Our method & $\operatorname{Ref}[21]$ & Our method & $\operatorname{Ref}[21]$ & Our method & $\operatorname{Ref}[21]$ \\
\hline 0.0 & 0 & 0 & 0 & 0 & 0.0000099 & 0 \\
\hline 0.1 & 0.0061 & 0.0129 & 0.0040 & 0.0068 & 0.0034 & 0.0049 \\
\hline 0.2 & 0.0244 & 0.0419 & 0.0187 & 0.0257 & 0.0168 & 0.0199 \\
0.3 & 0.0515 & 0.0834 & 0.0430 & 0.0555 & 0.0401 & 0.0449 \\
0.4 & 0.0863 & 0.1359 & 0.0763 & 0.0958 & 0.0733 & 0.0799 \\
\hline 0.5 & 0.1277 & 0.1983 & 0.1183 & 0.1463 & 0.1162 & 0.1248 \\
0.6 & 0.1753 & 0.2700 & 0.1686 & 0.2067 & 0.1686 & 0.1796 \\
0.7 & 0.2285 & 0.3502 & 0.2268 & 0.2768 & 0.2305 & 0.2443 \\
\hline 0.8 & 0.2868 & 0.4386 & 0.2926 & 0.3564 & 0.3015 & 0.3189 \\
0.9 & 0.3499 & 0.5347 & 0.3657 & 0.4452 & 0.3814 & 0.4032 \\
1.0 & 0.4173 & 0.6380 & 0.4458 & 0.5432 & 0.4699 & 0.4974 \\
\hline
\end{tabular}
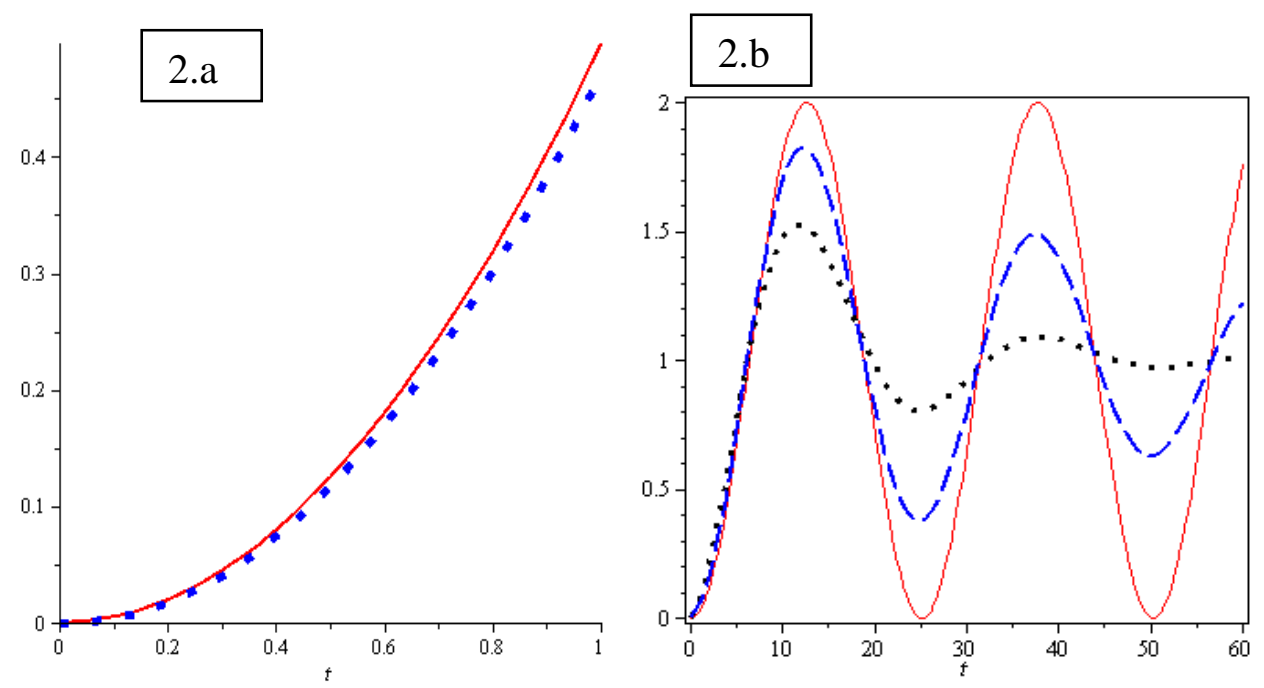

Figure 2. a. The solutions obtained by the wavelet method (- -) and analytical method $(-)$. with $\omega=0.25$.

Figure 2. b. The exact solution of a simple harmonic oscillator

$$
\alpha=2(-), \alpha=1.9(--), \alpha=1.7(\ldots) \text { by } \omega=0.25 \text {. }
$$

Figure 2 shows the numerical results for $\alpha=2, \alpha=1.9$ and $\alpha=1.7$. To try the impression of the function $f(t)=A$, the numerical solutions are evaluated by choosing $\mathrm{u}(0)=\mathrm{c}=0$ and $\mathrm{A}=1$. The behavior of the driven fractional oscillator for the step function is similar to that of the damped oscillator.

Example 3. In this example, assuming that the forcing function is $f(t)=\sin (\omega t)$, the fractional differential equation can be rewritten as: 
$\frac{d^{\alpha} u}{d t^{\alpha}}+\omega^{\alpha} u(t)=\sin (\omega t), \quad 1<\alpha \leq 2$,

by the initial conditions

$\mathrm{u}(0)=\mathrm{c}, \quad \dot{\mathrm{u}}(0)=0$,

By expressing $\mathrm{f}(\mathrm{t})$ in terms of Taylor series at $x=0$, one obtains;

$$
f(t)=\omega t-\frac{(\omega t)^{3}}{3 !}+\frac{(\omega t)^{5}}{5 !}-\frac{(\omega t)^{7}}{7 !}+L
$$

Thus, pursuant to CWM, the following is obtained;

$$
\frac{d^{\alpha}}{d t^{\alpha}}\left(\sum_{n=1}^{2^{k-1}} \sum_{m=0}^{M-1} c_{n, m} \psi_{n, m}(t)\right)+\omega^{\alpha}\left(\sum_{n=1}^{2^{k-1}} \sum_{m=0}^{M-1} c_{n, m} \psi_{n, m}(t)\right)=\omega t-\frac{(\omega t)^{3}}{3 !}+\frac{(\omega t)^{5}}{5 !}-\frac{(\omega t)^{7}}{7 !}+\cdots, \quad 1<\alpha \leq 2
$$

with;

$$
\begin{aligned}
& \sum_{\mathrm{n}=1}^{2^{k-1}} \sum_{\mathrm{m}=0}^{\mathrm{M}-1} \mathrm{c}_{\mathrm{n}, \mathrm{m}} \psi_{\mathrm{n}, \mathrm{m}}(0)=\mathrm{c} \\
& \sum_{\mathrm{n}=1}^{2^{k-1}} \sum_{\mathrm{m}=0}^{\mathrm{M}-1} \mathrm{c}_{\mathrm{n}, \mathrm{m}}\left(\frac{\mathrm{d}}{\mathrm{dt}} \psi_{\mathrm{n}, \mathrm{m}}(\mathrm{t})\right)(\mathrm{t}=0)=0
\end{aligned}
$$

The collocation points $\left\{t_{i}\right\}_{i=1}^{2^{k-1} M}$ are replaced at the above equations, such that;

$$
\frac{d^{\alpha}}{d t^{\alpha}}\left(\sum_{n=1}^{2^{k-1}} \sum_{m=0}^{M-1} c_{n, m} \psi_{n, m}\left(t_{i}\right)\right)+\omega^{\alpha}\left(\sum_{n=1}^{2^{k-1}} \sum_{m=0}^{M-1} c_{n, m} \psi_{n, m}\left(t_{i}\right)\right)=\omega t-\frac{(\omega t)^{3}}{3 !}+\frac{(\omega t)^{5}}{5 !}-\frac{(\omega t)^{7}}{7 !}+\cdots, \quad 1<\alpha \leq 2
$$

with the following initial conditions

$$
\begin{aligned}
& \sum_{\mathrm{n}=1}^{2^{k-1}} \sum_{\mathrm{m}=0}^{\mathrm{M}-1} \mathrm{c}_{\mathrm{n}, \mathrm{m}} \psi_{\mathrm{n}, \mathrm{m}}(0)=\mathrm{c}, \\
& \sum_{\mathrm{n}=1}^{2^{k-1}} \sum_{\mathrm{m}=0}^{\mathrm{M}-1} \mathrm{c}_{\mathrm{n}, \mathrm{m}}\left(\frac{\mathrm{d}}{\mathrm{dt}} \psi_{\mathrm{n}, \mathrm{m}}(\mathrm{t})\right)(\mathrm{t}=0)=0 .
\end{aligned}
$$


After computing the coefficients $\left\{\mathrm{c}_{n, m}\right\}$, the solutions $\mathrm{u}(\mathrm{t})$ are obtained for this equation. The numerical results of this problem with $\alpha=1.7, \alpha=1.9$ and $\alpha=2$ are shown in Table 3.

Table 3. Numerical results compared with the results in [21] by $\omega=0.01$.

\begin{tabular}{|c|c|c|c|c|c|c|}
\hline \multicolumn{3}{|c|}{$\alpha=1.7$} & \multicolumn{2}{|c|}{$\alpha=1.9$} & \multicolumn{2}{|c|}{$\alpha=2$} \\
\hline$l$ & Our method & $\operatorname{Ref[21]}$ & Our method & $\operatorname{Ref[21]~}$ & Our method & $\operatorname{Ref}[21]$ \\
\hline 0.0 & 0.00000002 & 0 & 0 & 0 & 0 & 0 \\
\hline 0.1 & 0.000006 & $\begin{array}{c}0.00000000 \\
1\end{array}$ & $\begin{array}{c}0.00000 \\
4\end{array}$ & 0.0000000003 & \multicolumn{2}{|c|}{$\begin{array}{c}0.000003 \\
0.0000000001\end{array}$} \\
\hline 0.2 & 0.00004 & 0.00000001 & 0.00003 & 0.000000002 & \multicolumn{2}{|c|}{$3 \quad 0.000000001$} \\
\hline 0.3 & 0.0001 & 0.00000003 & 0.0001 & 0.000000009 & 0.0001 & 0.000000004 \\
\hline 0.4 & 0.0003 & 0.00000007 & 0.0003 & 0.00000002 & 0.0002 & 0.00000001 \\
\hline 0.5 & 0.0006 & 0.0000001 & 0.0005 & 0.00000004 & 0.0005 & 0.00000002 \\
\hline 0.6 & 0.001 & 0.0000002 & 0.001 & 0.00000006 & 0.001 & 0.00000003 \\
\hline 0.7 & 0.001 & 0.0000003 & 0.001 & 0.00000010 & 0.001 & 0.00000005 \\
\hline 0.8 & 0.002 & 0.0000005 & 0.002 & 0.00000015 & 0.002 & 0.00000008 \\
\hline 0.9 & 0.003 & 0.0000007 & 0.003 & 0.00000022 & 0.003 & 0.00000012 \\
\hline 1.0 & 0.004 & 0.0000009 & 0.004 & 0.00000029 & 0.004 & 0.000000166 \\
\hline
\end{tabular}
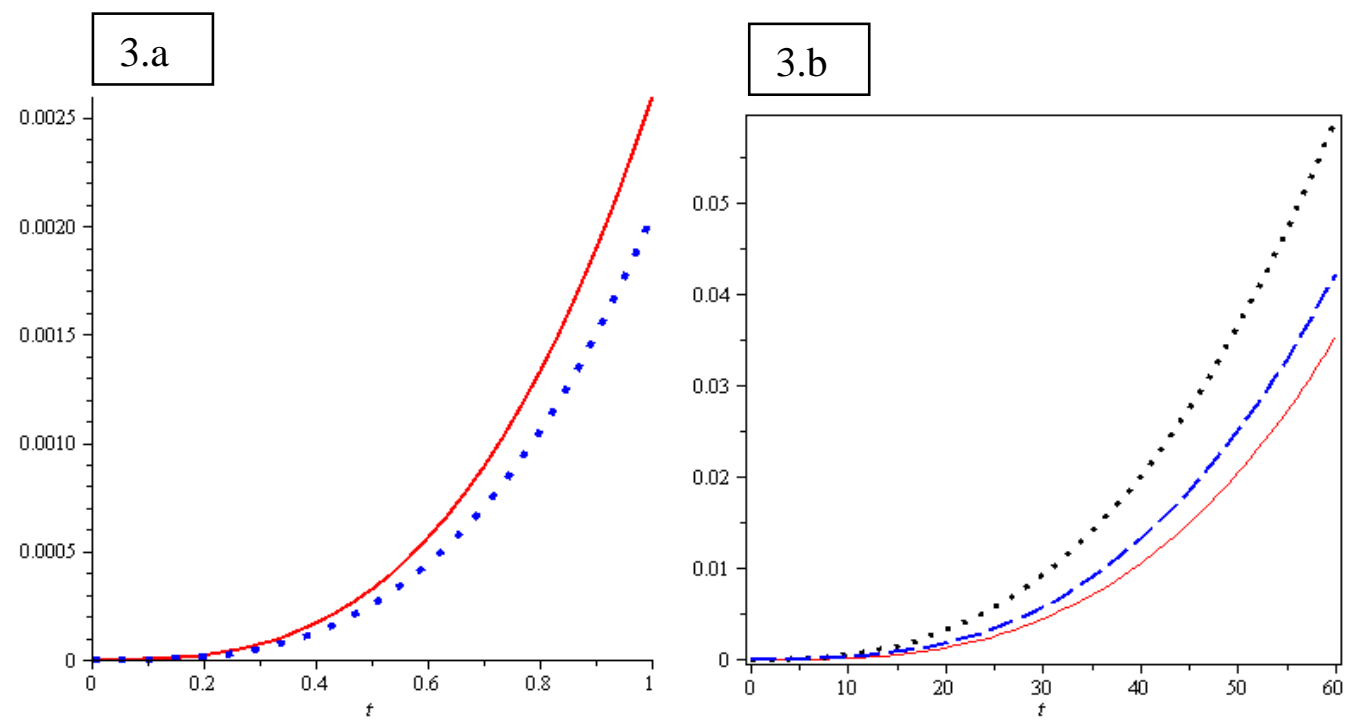

Figure 3. a. The solutions of obtained by the wavelet method (- -) and analytical method (-) with $\omega=0.25$.

Figure 3. b. The exact solution of a simple harmonic oscillator

$$
\alpha=2(-), \alpha=1.9(--), \alpha=1.7(\ldots) \text { by } \omega=0.01 \text {. }
$$


The results of this method for different values of $\alpha(1<\alpha \leq 2)$ and the sinusoidal function are convergent to the analytic solutions with $\alpha=2$. Also, Figure 3 shows the numerical results for $\alpha=2, \alpha=1.9$ and $\alpha=1.7$.

\section{Discussion}

The principal target of this paper was to compute numerical solutions for a system of driven oscillators. Several numerical methods were used for solving fractional differential equations, and the wavelet techniques were described as a numerical tool for the fast and accurate solution of these differential equations [9,19].

In the present work, the Chebyshev wavelet method was executed for solving fractional differential equations. Note that, in the Chebyshev wavelet method, the values of integrals were evaluated very accurately because; the bases of Chebyshev wavelets were polynomials of different orders. Thus, using this method, the problem was transformed to a system of nonlinear equations and satisfactory approximations were obtained for the solutions.

\section{Conclusions}

Numerical results proved higher ability of the proposed technique compared with that of the other methods. All the examples showed that the numerical results of the CWM were convergent to the exact solutions with $\alpha=2$. On the other hand, the obtained approximations demonstrated that the behavior of the driven fractional oscillator was similar to that of the damped harmonic oscillator. It can be concluded that the displacement functions are able to describe the intermediate processes between exponential decay $(\alpha=1)$ and pure sinusoidal oscillation $(\alpha=2)$.

\section{References}

[1] P. Fletcher, S. Haswell, and V. Paunov. Theoritical considerations of chemical reactions in micro-reactors operating under electro-osmotic and electrophoretic control, Analyst 124 (1991) 1273-1282.

[2] S. Muller. Adaptive Multiscale Schemes for Conversation Laws, Lecture Notes in Computational Science and Engineering, vol. 27, Springer, Berlin, 2003.

[3] G. Beylkin, and J. M. Keiser. On the Adaptive Numerical Solution of Nonlinear Partial Differential Equations in Wavelet Bases Can, Applied Math. Soc, JCP, 132 (1997)(CP965562), 233-259.

[4] J. M. Alam, N. K. R-. Kevlahan, and O. V. Vasilyev. Simultaneous Spacetime Adaptive Wavelet Solution of Nonlinear Parabolic Differential Equations, Journal of Computational Physics, 214 (2006) 829-857. 
[5] E. Hesameddini, and S. Shekarpaz. Wavelet solutions of the second painleve equation.,Iranian. J. of Science and Technology. prepared to publish, Vol.34. 2011. In press.

[6] C. K. Chui. Wavelets: A Mathematical Tool for Signal Analysis, SIAM, Philadelphia, PA, 1997.

[7] A. de Vries. Wavelets. FH Südwestfalen University of Applied Sciences, Haldener Straße 182, D-58095 Hagen, Germany Version: September 4, 2006.

[8] Oleg V. Vasilyev and W. Kendal Bushe. On the Use of a Dynamically Adaptive Wavelet Collocation Algorithm in Direct Numerica Simulations of Non-Premixed Turbulent Combustion, Center for Turbulence Research, Annual Research Briefs, 1998.

[9] E. Hesameddini, S. Shekarpaz, H. Latifizadeh and F. Fotros. An profitable algorithm to fractional differential equation: especially wave equations.,Int. J. of Differential equations. In press.

[10] L. Gagnon, and J. M. Lina. Wavelets and numerical split-step method: A global adaptive scheme, Opt. Soc. Am. B, to appear.

[11] J. Liandrat, V. Perrier, and Ph. Tchamitchian. Numerical Resolution of Nonlinear Partial Differential Equations using the Wavelet Approach. Wavelets and Their Applications, edited by M. B. Ruskai, G. Raphael (Jones \& Bartlett, Boston, 1992). print, 1996.

[12] R. L. Schult, and H. W. Wyld. Using wavelets to solve the Burgers' equation: A comparative study, Phys. Rev.A46, 12 (1992).

[13] Y. Luchko, and R. Gorne o. The initial value for some fractional differential equations with the caputo derivate, Preprint series A08-98, Fachbreich Mathematic and Informatic, Freic Universittal Berlin, 1998.

[14] K. S. Miller and B. Ross. An Introduction to the Fractional Calculus and Fractional Differential Equations, Wiley, New York, 1993.

[15] L. Blank. Numerical treatment of differential equations of fractional order, MCCM Numerical Analysis Rep. 287, The University of Manchester, 1996.

[16] R. Goreno, and F. Mainardi. Fractional calculs. Integral and differential equations of fractional order in Fractals and Fractional Calculus in Continuum Mechanics, A Carpinter and F. Mainardi, eds., Springer-Verlag. New Nork 1997.

[17] F. Mainradi. Fractional relaxation-oscillation and fractional diffusion-wave phenomena, Chaos Solitons Fractals 7(9) (1996) pp. 1461-1477.

[18] F. Mainradi. Fractional calculus: Some basic problems in continuum and statistical mechanics, in Fractals and Fractional Calculus in Continuum Mechanics, A Carpinteri and F. Mainradi, eds., Springer-Verlag, New York, 1997, pp. 291-348.

[19] Yuanlu Li. Solving a nonlinear fractional differential equation using Chebyshev wavelets., J. Commun Nonlinear Sci Numer Simulat 15 (2010) 2284-2292. 
[20] E. Babolian and F. Fattahzadeh. Numerical computation method in solving integral equations by using Chebyshev wavelet operational matrix of integration., Applied Math and Comput. 188 (2007) 1016-1022.

[21] A. Yildirim and S. Momani. Series solutions of a fractional oscillator by means of the homotopy perturbation method, Int. J. of Computer Mathematics. Vol 87, No 5, April 2010, 1072-1082. 